\title{
Development of an Efficient Genotyping Method to Detect Obese Mutation in the Mouse Leptin Gene for Use in SPF Barrier Facilities
}

\author{
Hiroaki AYABE ${ }^{1) *}$, Shogo IKEDA ${ }^{2}$, Shigeri MARUYAMA ${ }^{3)}$, Seiji SHIOYAMA ${ }^{4)}$, Mayumi KIKUCHI ${ }^{3)}$, \\ Ayako $\mathrm{KAWAGUCHI}^{3)}$, Tetsuo YAMADA ${ }^{5)}$ and Takuya IKEDA ${ }^{6)}$ \\ 1) Production Department, Plasma Team, CHARLES RIVER LABORATORIES JAPAN, Inc., 795 Shimofurusawa, Atsugi-shi, Kanagawa \\ 243-0214, Japan \\ 2) Department of Biochemistry, Faculty of Science, Okayama University of Science, 1-1 Ridaicho, Kita-ku, Okayama-shi, Okayama \\ 700-0005, Japan \\ 3) Monitoring Center, CHARLES RIVER LABORATORIES JAPAN, Inc., 4049-3 Nakatsu, Aikawa-machi, Aikou-gun, Kanagawa 243-0303, \\ Japan \\ 4)Tsukuba Breeding Center, CHARLES RIVER LABORATORIES JAPAN, Inc., 955 Kamibayashi, Ishioka-shi, Ibaraki 315-0138, Japan \\ ${ }^{5)}$ Hino Breeding Center, CHARLES RIVER LABORATORIES JAPAN, Inc., 735 Shimokomaduki, Hino-cho, Gamou-gun, Shiga 529-1633, \\ Japan \\ 6) Production Department, CHARLES RIVER LABORATORIES JAPAN, Inc., 3-17-6 Shin-Yokohama, Kohoku-ku, Yokohama-shi, \\ Kanagawa 222-0033, Japan
}

(Received 3 August 2012/Accepted 26 November 2012/Published online in J-STAGE 10 December 2012)

ABSTRACT. We have developed a rapid and efficient genotyping method for detection of the mouse leptin obese mutation $\left(\right.$ Lep $\left.^{o b}\right)$ using tetra-primer amplification refractory mutation system-polymerase chain reaction (tetra-primer ARMS-PCR). In this method, whole blood collected onto gamma-ray sterilized Flinders Technology Associates (FTA) filter paper is used as PCR template without a DNA purification step. Three genotypes $\left(\mathrm{Lep}^{o b} / \mathrm{Lep}^{o b}, \mathrm{Lep}^{o b} /+\right.$ and $+/+$ ) differentiated by single-tube PCR and electrophoresis were perfectly consistent with those determined by PCR-restriction fragment length polymorphism (PCR-RFLP). This method can save material costs and operation time, because it does not require restriction enzyme digestion and could be set up in most specific pathogen-free (SPF) barrier facilities. KEY WORDS: genotyping, mouse $L e p^{o b}$ mutation, SPF barrier facility, sterilization of FTA filter paper, tetra-primer ARMS-PCR

doi: 10.1292/jvms.12-0348; J. Vet. Med. Sci. 75(5): 633-638, 2013

Because of their short generation times and high breeding efficiency, rodents are extremely useful for researching disorders $[2,12]$. Point mutation-carrying strains, such as mice with an obese mutation in the leptin gene $\left(\operatorname{Lep}^{o b}\right)$ [16] and rats with a fatty mutation in the leptin receptor gene (Lepr $\left.{ }^{f a}\right)$, [13] are included in representative rodent disease models [6]. For authentic research and for maintaining strains, it is important to verify the existence of point mutations.

Tetra-primer amplification refractory mutation systempolymerase chain reaction (tetra-primer ARMS-PCR) employs 2 primer pairs to amplify, respectively, the 2 different alleles of a single nucleotide polymorphism (SNP) in a single PCR [15]. Moreover, the primers can be designed to amplify fragments of differing sizes for each allele [15]. Therefore, tetra-primer ARMS-PCR does not require restriction enzyme digestion and allows genotyping of a point mutation solely by inspection of PCR products with agarose gel electrophoresis. Combining Flinders Technology Associates (FTA) filter paper and appropriate PCR buffer allows for direct PCR amplification of DNA from unpurified blood on FTA filter

*Correspondence to: Ayabe, H., Special Animal Service, CHARLES RIVER LABORATORIES JAPAN, Inc., 4049-3 Nakatsu, Aikawa-machi, Aikou-gun, Kanagawa 243-0303, Japan. e-mail: hiroaki.ayabe@crl.com

(C)2013 The Japanese Society of Veterinary Science paper [7]. To use FTA filter paper in our specific pathogenfree (SPF) barrier facility, we have so far used ethylene oxide gas (EOG) sterilization. However, ethylene oxide is a directly acting alkylating agent which is associated with an increase in chromosomal aberrations and sister chromatid exchange $[1,5]$. On the other hand, radiation leaves no toxic residues on treated medical items [10]. Here, we describe a rapid and efficient point mutation genotyping of the mouse leptin gene using tetra-primer ARMS-PCR and gamma-ray sterilized FTA filter paper in SPF barrier facilities.

All procedures involving the use of mice were approved by the animal welfare committee of CHARLES RIVER LABORATORIES JAPAN. FTA filter paper (GE Healthcare Japan, Tokyo, Japan) was sterilized with EOG or with gamma-ray irradiation and carried into our in-house vivarium. Future breeders of the SPF B6.Cg- $\mathrm{Lep}^{o b} / \mathrm{J}$ strain (CHARLES RIVER LABORATORIES JAPAN, Yokohama, Japan), housed in the in-house vivarium, were used when weaning age. A small drop of whole blood, exuded by cutting the mice tail within $1 \mathrm{~mm}$ in length from the end, was spotted onto FTA filter paper and dried at room temperature. Cutting of mice tail was quickly performed only once with the minimum incision required for blood collection. The FTA filter paper was placed into a zippered product package together with silica gel for storage and shipping. The blood samples, covering about $0.9 \mathrm{~mm}^{2}$ of FTA filter paper, were punched out using a KN-292B ear puncher (1.5-mm diam- 


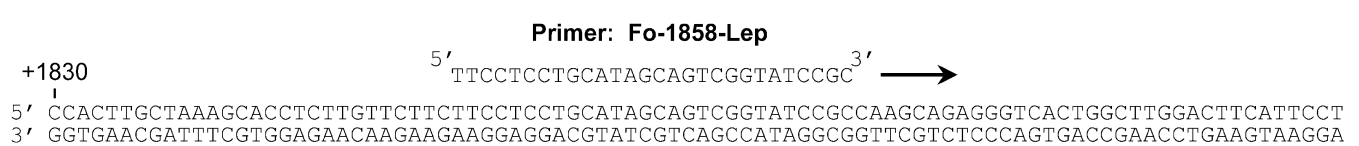

3' GGTGAACGATTTCGTGGAGAACAAGAAGAAGGA GACGTATCGTCAGCCATAGGCGGTTCGTCTCCCAGTGACCGAACCTGAAGTAAGGA

GGGCTTCACCCCATTCTGAGTTTGTCCAAGATGGACCAGACTCTGGCAGTCTATCAACAGGTCCTCACCAGCCTGCCTTCCCAAAATGTG CCCGAAGTGGGGTAAGACTCAAACAGGTTCTACCTGGTCTGAGACCGTCAGATAGTTGTCCAGGAGTGGTCGGACGGAAGGGTTTTACAC

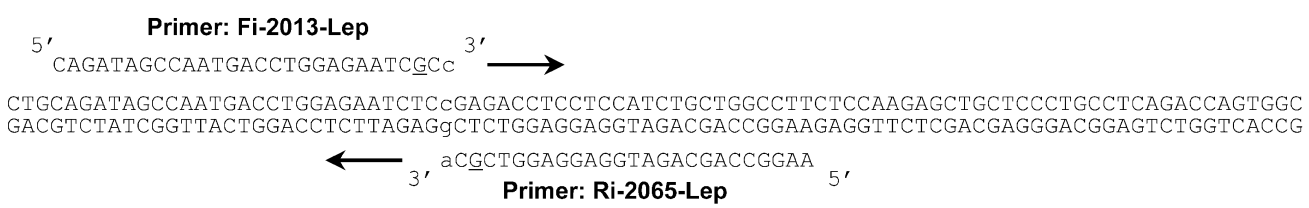

CTGCAGAAGCCAGAGAGCCTGGATGGCGTCCTGGAAGCCTCACTCTACTCCACAGAGGTGGTGGCTTTGAGCAGGCTGCAGGGCTCTCTG GACGTCTTCGGTCTCTCGGACCTACCGCAGGACCTTCGGAGTGAGATGAGGTGTCTCCACCACCGAAACTCGTCCGACGTCCCGAGAGAC

CAGGACATTCTTCAACAGTTGGATGTTAGCCCTGAATGCTGAAGTTTCAAAGGCCACCAGGCTCCCAAGAATCATGTAGAGGGAAGAAAC 3' GTCCTGTAAGAAGTTGTCAACCTACAATCGGGACTTACGACTTCAAAGTTTCCGGTGGTCCGAGGGTTCTTAGTACATCTCCCTTCTTTG 5' $\longleftarrow_{3}{ }^{\text {GACTTCAAAGTTTCCGGTGGTCCGAGGG }}$ Primer: Ro-2255-Lep $^{\prime}$

Fig. 1. Base sequence of mouse leptin gene and positions of primers used for tetra-primer ARMS-PCR. Nucleotide bases are numbered from the A of the initiator methionine ATG codon as +1 . Lowercase letters indicate SNP on the mouse leptin gene. Underlines indicate artificial mismatched bases on primers.

eter; Natsume Seisakusho, Tokyo, Japan), and used as template DNAs for PCR. The punched filter paper was placed directly in $20 \mu l$ of PCR mixture. PCR was carried out using a 2720 Thermal Cycler (Life Technologies, Carlsbad, CA, U.S.A.). Genomic DNA was purified with a Get pureDNA kit-Cell, Tissue (Dojindo Laboratories, Kumamoto, Japan) according to the manufacturer's instructions, and $10 \mathrm{ng}$ of the DNA was added to $20 \mu l$ of PCR mixture as the template for the positive control. The mixture for tetra-primer ARMSPCR contained $1 \times$ Ampdirect plus (providing a final concentration of $1.5 \mathrm{mM} \mathrm{MgCl} 2$ and $200 \mu \mathrm{M}$ dNTPs; Shimadzu Corporation, Kyoto, Japan), additional $1.5 \mathrm{mM} \mathrm{MgCl}_{2}$, $0.0175 \mathrm{U} / \mu l$ BIOTAQ HS DNA polymerase (BIOLINE, London, UK) and four primers designed by our group $(0.5$ $\mu \mathrm{M}$ Fo-1858-Lep, $0.5 \mu \mathrm{M}$ Ro-2255-Lep, $0.1 \mu \mathrm{M}$ Fi-2013Lep and $0.1 \mu \mathrm{M}$ Ri-2065-Lep). The sequence and position of the primers are shown in Fig. 1. The cycling conditions for tetra-primer ARMS-PCR began with an initial denaturation at $95^{\circ} \mathrm{C}$ for $10 \mathrm{~min}$ followed by 35 cycles of $95^{\circ} \mathrm{C}$ for 15 sec, $65^{\circ} \mathrm{C}$ for $30 \mathrm{sec}$ and elongation at $72^{\circ} \mathrm{C}$ for $45 \mathrm{sec}$. After cycling, a final elongation period at $72^{\circ} \mathrm{C}$ was performed for 2 min. The tetra-primer ARMS-PCR products were electrophoresed on a $4 \%$ agarose gel (Reliant 4\% NuSieve 3:1 Plus Agarose gels; Lonza, Basel, Switzerland) and stained with ethidium bromide. The PCR mixture of PCR-RFLP contained $1 \times$ Ampdirect plus, $0.025 \mathrm{U} / \mu l$ BIOTAQ HS DNA polymerase, $0.5 \mu \mathrm{M}$ oIMR1151 primer (5'-TGTCCAAGATGGACCAGACTC-3') and $0.5 \mu \mathrm{M}$ oIMR1152 primer (5'-ACTGGTCTGAGGCAGGGAGCA-3') in $20 \mu \mathrm{l}$. The PCR-RFLP primers were synthesized according to the Jackson Laboratory's genotyping protocol [14]. The PCR cycling conditions for PCR-RFLP began with an initial denaturation at $95^{\circ} \mathrm{C}$ for $10 \mathrm{~min}$ followed by 40 cycles of $94^{\circ} \mathrm{C}$ for $15 \mathrm{sec}$, $62^{\circ} \mathrm{C}$ for $30 \mathrm{sec}$ and $72^{\circ} \mathrm{C}$ for $45 \mathrm{sec}$. After cycling, a final elongation period at $72^{\circ} \mathrm{C}$ was performed for $2 \mathrm{~min}$. Ten $\mu l$ of PCR products was digested with $10 \mathrm{U}$ of $D d e$ I restriction enzyme (New England Biolabs, (Ipswich, MA, U.S.A.) in a total volume of $20 \mu \mathrm{l}$ at $37^{\circ} \mathrm{C}$ for $1 \mathrm{hr}$ and then subjected to electrophoresis on a $4 \%$ agarose gel.

We designed tetra-primer ARMS-PCR primers for amplification of allele-specific PCR products from wild-type (WT; $+)$ and mutant $\left(L e p^{o b}\right)$ alleles in addition to an internal control product from both alleles to check the performance of PCR (Fig. 1). The tetra-primer ARMS-PCR method is based on the finding that oligonucleotides with a mismatched 3 ' residue will not function as primers in PCR under appropriate conditions using DNA polymerase lacking $3^{\prime}$ to $5^{\prime}$ exonuclease activity $[9,15]$. In our tetra-primer ARMS-PCR, a 243-bp PCR product will be specifically amplified from the WT allele by Fi and Ro primers and a 208-bp PCR product from the $L e p^{o b}$ mutant allele by Fo and Ri primers (Fig. 2). In addition, a 398-bp PCR product will be amplified from both alleles by Fo and Ro primers as an internal control. The three PCR products differ in length, allowing them to be discriminated by agarose gel electrophoresis.

Three genotypes $\left(L e p^{o b} / L e p^{o b}, L e p^{o b} /+\right.$ and $+/+$ ) of the $L e p^{o b}$ mouse generated after mating heterozygous mice were differentiated with the tetra-primer ARMS-PCR (Fig. 3). As expected, 398-bp and 243-bp PCR products were amplified from +/+ WT mice, 398-bp and 208-bp products from $L e p^{o b /}$ $\mathrm{Lep}^{o b}$ mice, and 398-bp, 243-bp and 208-bp products from $\mathrm{Lep}^{o b /+}$ mice. PCR-RFLP was also performed using the same samples to authenticate the genotypes. The genotypes determined by tetra-primer ARMS-PCR were perfectly consistent with those determined by PCR-RFLP. The PCR products using FTA filter paper as template DNA were efficiently 


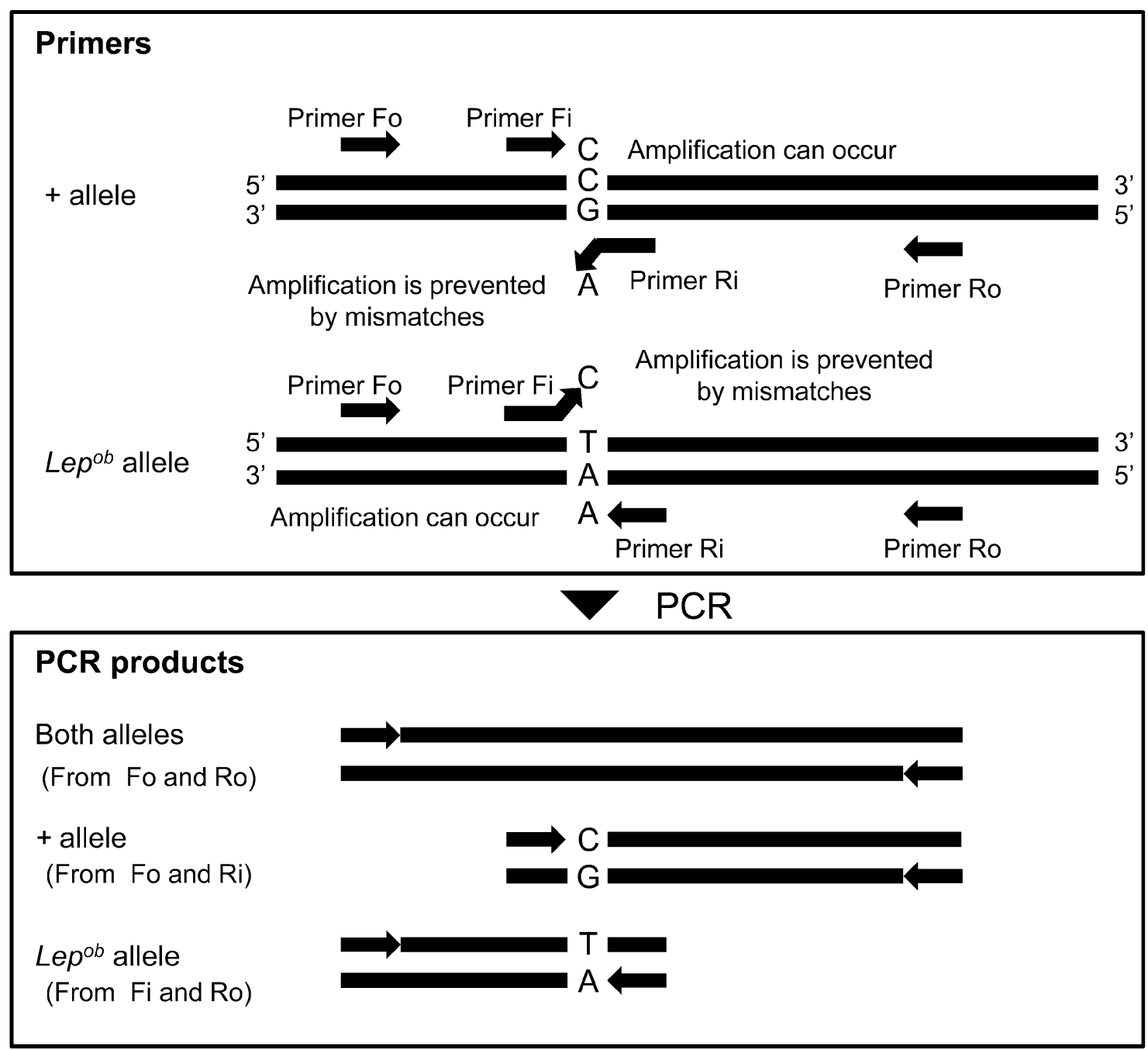

$\nabla$ Electrophoresis

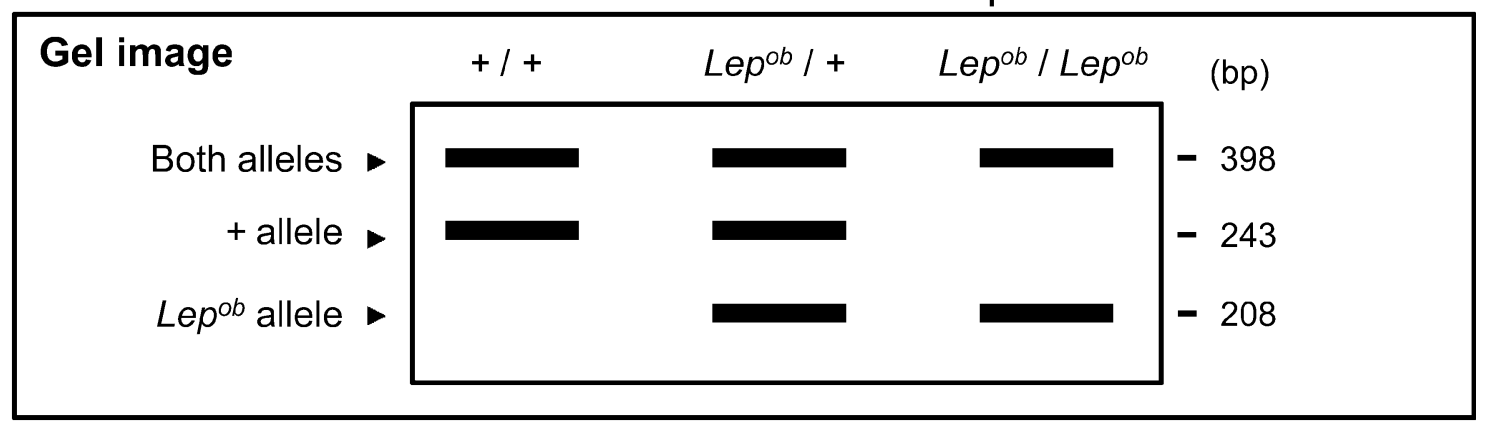

Fig. 2. Experimental design for determination of mouse leptin gene $\left(L e p^{o b}\right)$ genotypes with tetra-primer ARMS-PCR. Wild type $(+)$ allele-specific PCR product could be amplified by Fi and Ro primers. Lep ${ }^{o b}$ allele-specific product could be amplified by Fo and Ri primers. Products from Fo and Ro primers served as PCR internal controls from both alleles. Details of allele-specific amplification are described in the text.

amplified, as were those using purified genomic DNA as template. Seventy-seven of 290 mice generated after mating heterozygous mice which were genotyped by tetra-primer ARMS-PCR showed obesity. The ratio agrees well with ex- pected ratio of $1: 3\left(\chi^{2}\right.$ test, $\left.P=0.54\right)$. The all mice genotyped as $L e p^{o b} / L e p^{o b}$ developed obesity. Some genotyping methods have been reported to detect the mouse $L e p^{o b}$ mutation, which includes PCR-RFLP [4], allele-specific primer-PCR 


\section{A) tetra-primer ARMS-PCR}

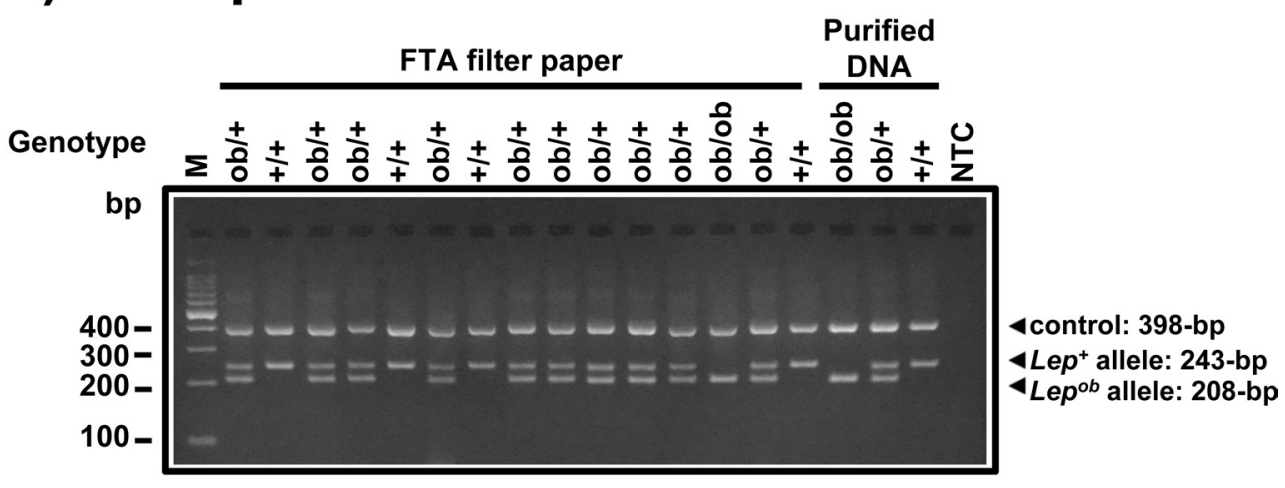

\section{B) PCR-RFLP}

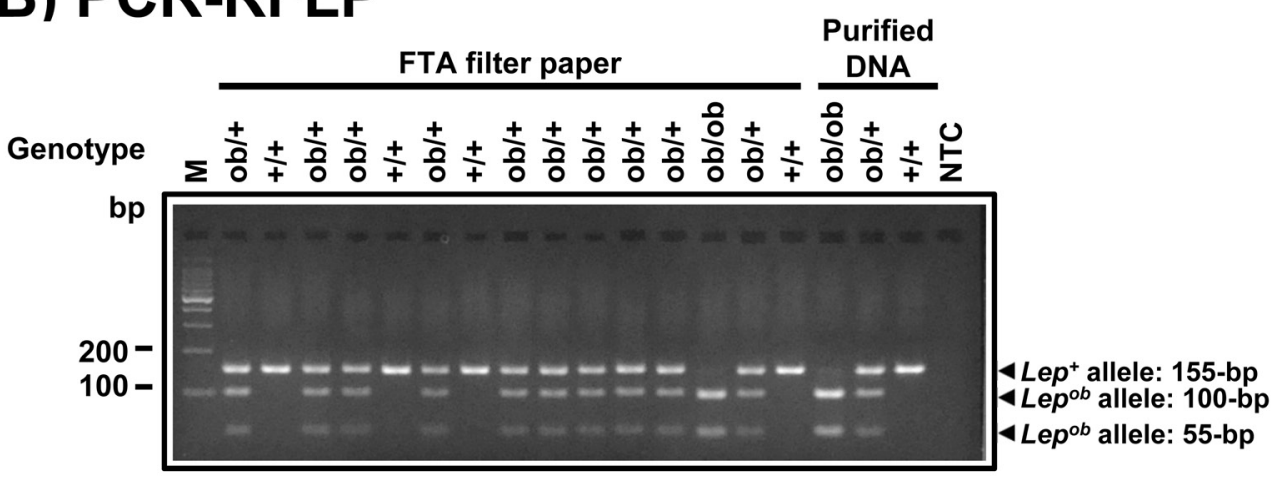

Fig. 3. Genotyping of the obese mutation in the mouse leptin gene $\left(L e p^{o b}\right)$ by tetra-primer ARMS-PCR and PCR-RFLP. Future breeders of B6.Cg-Lep ${ }^{o b} / \mathrm{J}$ mice were genotyped by tetra-primer ARMS-PCR (A) and PCR-RFLP (B) using the same samples. Whole blood collected onto FTA filter paper or purified genomic DNAs were used as PCR templates. M: Molecular size marker, 100 bp DNA ladder (Takara, Shiga, Japan). NTC: No template control.

Table 1. Material cost and operation time in tetra-primer ARMS-PCR and PCR-RFLP

\begin{tabular}{|c|c|c|c|c|}
\hline \multirow[b]{2}{*}{ Procedure } & \multicolumn{2}{|c|}{ PCR-RFLP } & \multicolumn{2}{|c|}{ tetra-primer ARMS-PCR } \\
\hline & $\begin{array}{c}\text { Material costa } \\
(\%)\end{array}$ & $\begin{array}{l}\text { Operation time } \mathrm{e}^{\mathrm{b})} \\
(\mathrm{min})\end{array}$ & $\begin{array}{c}\text { Material } \operatorname{cost}^{\mathrm{a})} \\
(\%)\end{array}$ & $\begin{array}{l}\text { Operation time }{ }^{\mathrm{b}} \\
(\mathrm{min})\end{array}$ \\
\hline PCR & 27 & 140 & 27 & 140 \\
\hline Restriction enzyme digestion & 50 & 70 & 0 & 0 \\
\hline Electrophoresis & 23 & 30 & 23 & 40 \\
\hline Total & 100 & 240 & 50 & 180 \\
\hline
\end{tabular}

a) Total material cost of PCR-RFLP was set at $100 \%$, and all other material costs were calculated relative to this value.

b) Operation time of PCR includes the time required for punching 96 samples from FTA filter paper and thermal cycling. Restriction digestion includes the time for preparation of the reaction mixture and the time for the reaction. Electrophoresis includes the time for loading samples and running time.

[8], PCR amplification of specific alleles [3] and the Invader Plus assay [11]. Unlike these methods, this method does not require restriction enzyme digestion, one reaction for each allele or any special equipment. In fact, this method reduces material costs by $50 \%$ as well as operating time by $25 \%$ in comparison with PCR-RFLP (Table 1). These results suggest that tetra-primer ARMS-PCR developed in this study is able to accurately distinguish the point mutation site at a low cost. Additionally, the change of primer set could enable genotyping of various point mutations.

FTA filter paper is impregnated with a patented chemical formula that lyses cell membranes and denatures proteins on contact. Nucleic acids are physically entrapped, immobilized and stabilized for storage at room temperature on FTA 

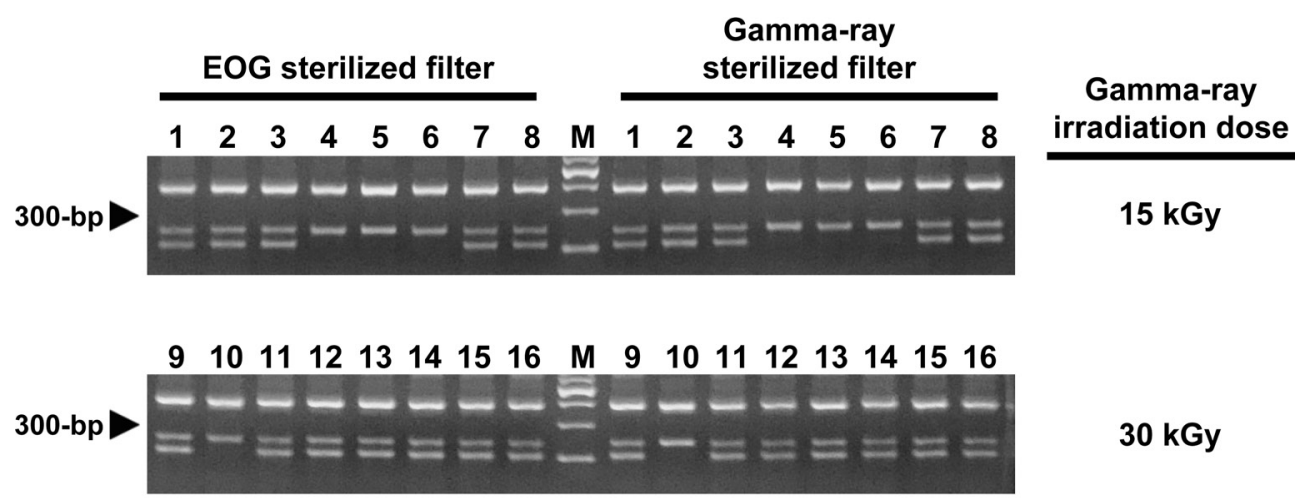

30 kGy

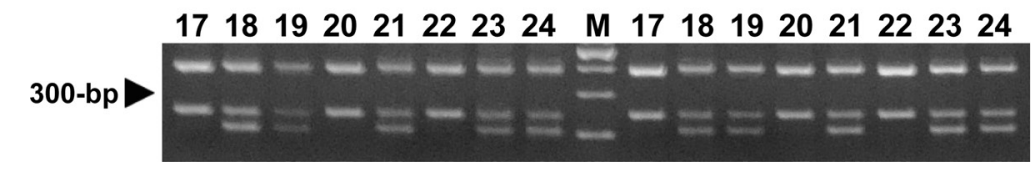

45 kGy

Fig. 4. Influence of the sterilization method of FTA filter paper on PCR. FTA filter papers were sterilized with 15,30 and $45 \mathrm{kGy}$ of gamma-rays. Whole blood collected from future breeders of B6.Cg- $L e p^{o b} / \mathrm{J}$ mice were spotted on the filters and used as templates of tetra-primer ARMS-PCR. The same blood samples on FTA filter papers sterilized with EOG were also prepared as the comparative control. The numbers indicate individual mice. M: Molecular size marker, 100 bp DNA ladder (Takara, Otsu, Japan).

filter paper. Additionally, FTA filter paper protects nucleic acids from nucleases, oxidation, UV damage and microbial attack. Here, we performed sterility testing of gamma-raysterilized FTA filter paper. Bacillus pumilus (ATCC 27142) spore strips (NAMSA, Northwood, OH, U.S.A.) and FTA filter papers were placed in a cardboard box, and were then irradiated with 15, 30 and $45 \mathrm{kGy}$ of gamma-rays using a cobalt-60 source (Japan Irradiation Service, Tokyo, Japan). After irradiation, the spore strips were placed in Trypto-soy buillon broth (Eiken Chemical, Tokyo, Japan) and incubated at $37^{\circ} \mathrm{C}$ for 2 weeks. No positive growth was observed in spore strips irradiated with 15,30 and $45 \mathrm{kGy}$. On the other hand, the non-irradiated positive control indicated positive growth after one day of incubation. These results suggest that irradiation of $15 \mathrm{kGy}$ would be sufficient to sterilize FTA filter paper required in the SPF barrier facility. We also studied the influence of the sterilization method of FTA filter paper on PCR. Unopened FTA filter papers were sterilized with 15,30 and $45 \mathrm{kGy}$ of gamma-rays and were sprayed with Clidox-S (Pharmacal Research Labs, Naugatuck, CT, U.S.A.). After 8 weeks, blood samples were collected on the FTA filter paper in our research vivarium. FTA filter papers sterilized with EOG were used as the comparative control. The blood samples on FTA filter papers were kept at room temperature for seven days, and used for tetra-primer ARMS-PCR. The genotypes determined using FTA filter papers irradiated with 15,30 and $45 \mathrm{kGy}$ were completely consistent with those determined using the EOG sterilized filter (Fig. 4). These results suggest that EOG sterilization of FTA filter paper could be replaced by gamma-ray sterilization.

Consequently, the mouse $L e p^{o b}$ genotyping method us- ing gamma-ray sterilized FTA filter paper and tetra-primer ARMS-PCR is considered to be a rapid and efficient method for use in an SPF barrier facility. Since this genotyping method does not require any special equipment, it could be set up in most SPF barrier facilities. Additionally, the change of primer set could enable genotyping of various point mutations.

ACKNOWLEDGMENT. We thank Dr. Tsunemichi Hosokawa for his encouragement and advice.

\section{REFERENCES}

1. Cuarón, A. 1994. Nuclear applications for health: Keeping pace with progress. IAEA Bulletin 36: 2-9.

2. Dwinell, M. R. 2010. Online tools for understanding rat physiology. Brief. Bioinform. 11: 431-439. [Medline] [CrossRef]

3. Ellett, J. D., Evans, Z. P., Zhang, G., Chavin, K. D. and Spyropoulos, D. D. 2009. A rapid PCR-based method for the identification of $o b$ mutant mice. Obesity 17: 402-404. [Medline]

4. Hirasawa, T., Ohara, T. and Makino, S. 1997. Genetic typing of the mouse $o b$ mutation by PCR and restriction enzyme analysis. Exp. Anim. 46: 75-78. [Medline] [CrossRef]

5. IARC 1994. Ethylene oxide. pp. 73-159. In: Some Industrial Chemicals. IARC Monographs on the Evaluation of Carcinogenic Risks to Humans 60, IARC Press, Lyon.

6. Kanasaki, K. and Koya, D. 2011. Biology of obesity: lessons from animal models of obesity. J. Biomed. Biotechnol. 2011: 1-11. [Medline] [CrossRef]

7. Nakanishi, S., Kuramoto, T. and Serikawa, T. 2009. Simple genotyping method using Ampdirect Plus and FTA technologies: application to the identification of transgenic animals and their routine genetic monitoring. Lab. Anim. Res. 25: 75-78.

8. Namae, M., Mori, Y., Yasuda, K., Kadowaki, T., Kanazawa, Y. 
and Komeda, K. 1998. New method for genotyping the mouse $L e p^{o b}$ mutation, using a polymerase chain reaction assay. Lab. Anim. Sci. 48: 103-104. [Medline]

9. Newton, C. R., Graham, A., Heptinstall, L. E., Powell, S. J., Summers, C., Kalsheker, N., Smith, J. C. and Markham, A. F. 1989. Analysis of any point mutation in DNA. The amplification refractory mutation system (ARMS). Nucleic Acids Res. 17: 2503-2516. [Medline] [CrossRef]

10. Nofal, M. 1987. Radiation for better health. IAEA Bulletin 29: 43-49.

11. Oler, A. T. and Attie, A. D. 2008. A rapid, microplate SNP genotype assay for the leptin ${ }^{o b}$ allele. J. Lipid Res. 49: 1126-1129. [Medline] [CrossRef]

12. Peltonen, L. and McKusick, V. A. 2001. Genomics and medicine. Dissecting human disease in the postgenomic era. Science 291: 1224-1229. [Medline] [CrossRef]

13. Takaya, K., Ogawa, Y., Isse, N., Okazaki, T., Satoh, N., Masu- zaki, H., Mori, K., Tamura, N., Hosoda, K. and Nakao, K. 1996. Molecular cloning of rat leptin receptor isoform complementary DNAs-identification of a missense mutation in Zucker fatty (fa/ fa) rats. Biochem. Biophys. Res. Commun. 225: 75-83. [Medline] [CrossRef]

14. The Jackson Laboratory "Genotyping protocols database", available from<http://jaxmice.jax.org/protocolsdb/ $\mathrm{f} ? P=116: 2: 829867545943552:$ NO:2:P2_MASTER_PROTOCOL_ID,P2_JRS_CODE:551,000632>, (accessed 2012-11-12).

15. Ye, S., Dhillon, S., Ke, X., Collins, A. R. and Day, I. N. 2001. An efficient procedure for genotyping single nucleotide polymorphisms. Nucleic Acids Res. 29: e88. [Medline] [CrossRef]

16. Zhang, Y., Proenca, R., Maffei, M., Barone, M., Leopold, L. and Friedman, J. M. 1994. Positional cloning of the mouse obese gene and its human homologue. Nature 372: 425-432. [Medline] [CrossRef] 